\title{
Region ethnoeconomies: development barriers, state support
}

\section{potential,}

\author{
Elena Klochko, ${ }^{1, *}$, Elena Vorobey $^{2}$ and Rustem Shichiyakh ${ }^{1}$ \\ ${ }^{1}$ Kuban State Agricultural University, ul. Kalinina, 13, Krasnodar, 350004, Russia \\ ${ }^{2}$ Sochi State University, ul. Sovetskaya, 26A, Sochi, 354000, Russia
}

\begin{abstract}
In article, development of ethnoeconomy is considered as a possibility of overcoming an imbalance in the agrarian sector of the Russian Federation. The carried-out analysis of the definition "ethnoeconomy" has revealed the need of addition of innovative component in interpretation of this term. It will allow giving a new look to traditional forms of managing or carrying out production of ethnic goods according to the latest technologies. Prospects of a clustering of business activity in the sphere of ethnic economy in Krasnodar Region are considered. It is defined that it promotes increase in efficiency of interaction of subjects of small and medium business and also growth of their internal potential in modern economic conditions. It is revealed that the lack of infrastructure for realization of the ethnic production is one of the main problems of ethnic economy of any region of the Russian Federation. The authors consider that "successful" ethnic production should have a certain popularity, to be eco-friendly, to conform to the quality standards, and to possess original packing. The authors have considered theoretical prerequisites of formation of the Cossack farms of innovative type as innovative elements of economic space of the territory.
\end{abstract}

\section{Introduction}

Today, one of the most burning issues in the Russian Federation is poverty and employment of country people. This problem arose during transition from a command control system to market conditions of managing. The task of decrease in volume of import of agricultural products and improvement of food supply of the population is set for the state. For overcoming an imbalance in the agrarian sector of the country in the conditions of economic sanctions, use of internal reserves is of particular importance. One of such reserves is development of alternative types of agricultural activity in rural territories, taking into account specifics of the region of the country. Revival of the village is possible due to development of various branches of ethnoeconomy of our country. Let's note existence of positive experience of functioning of territories with ethnic orientation in the Russian Federation.

The concept "ethnoeconomy" is considered as employment of people on production of the traditional goods and services, especial of a certain territory. Many scientists understand

\footnotetext{
*Corresponding author: magadan.79@mail.ru
} 
a specific form of national economy as «ethnoeconomy". Although, "ethnoeconomy" is the certain segment of national economy selected by the traditional types of activity inherent to this ethnic community. In our opinion, the ethnoeconomy is a science about interaction of culture, traditions, ethnos, customs, ideologies, religious views of the different nations with their economic activity. Let's note that certain characteristics are inherent in ethnoeconomy. This existence of the natural forms of managing closed within a household, agrarian orientation. Natural forms of managing are capable to be transformed for the purpose of creation of competitive advantages of the territory.

Expanded approach to ethnoeconomy opens its entity, however is not full. Let's add to expanded treatment the innovation to a component that will allow traditional forms of managing to carry out production of ethnic goods according to the latest technologies.

\section{Materials and Methods}

The methodology of regional economy that laying the foundation for forming theoretical model of functioning of ethnoeconomy in economic space of the territory is formulated by A.G. Granberg [1], Yu.S. Kolesnikov [2], V.N. Ovchinnikov's [3]. Ethnoeconomic aspects of development of economic systems in the conditions of globalization are considered in the works by V.Ya. Akhmetov [4], S.V. Panikarova [5], N.M. Surnina [6], O.V. Pechura [7]. It's necessary to note the variety and diversity of approaches to disclosure of the separate parties of the subject outlined in a research. However, theoretic and methodological and applied aspects of a research of a phenomenon of ethnoeconomy as the localized economic system of mesolevel making territorial still remained on the periphery of scientific search.

In article, methods of a system, monographic, structural and logical research, method of expert evaluations are used.

\section{Results}

Let's allocate the main functions which are performed by ethnoeconomy:

- the stabilization function allowing ethnoeconomy to act as a framework of the agrarian sphere of multinational economy;

- the social and economic functions allowing ethnoeconomy to reduce unemployment of the population in the village;

- the function of maintaining tradition promoting complex use of continuity and innovation of development of the region;

- the depreciation function smoothing various negative impacts of the environment on region economy.

Ethnic components in economy allow gaining synergetic effect and increasing competitive advantages of the region. Traditional households should not carry out a role of ethnic reservations in which traditions of a certain ethnos are preserved.

In research, it is necessary to consider an ethnic component of capacity of the territory. Let's allocate elements of ethnoeconomic capacity of the territory:

1) the social element which is closely connected with historical and sociocultural elements. Ethnic component explains the reasons of unity of the certain groups of the population living in the region. The certain civilization code identifying ethnos among other ethnos is inherent in these groups. A historical component allows understanding continuity of the traditions which developed at a certain ethnos. These traditions are expressed in economic or administrative tenor of life of ethnos; 
2) the economic element implies existence of a certain market interaction of ethnos within the region. In case if it is possible to speak about need of production of a certain competitive ethnic product. It is impossible to forget about innovative component of ethnoeconomic potential. Otherwise, ethnic reproduction can roll down in the closed forms of managing [2]. The ethnoeconomy acts as a certain regional stabilizer which allows indigenous people to generate impulses of development of the territory;

3 ) the organizational element includes two interconnected factors: structural and institutional. Thanks to a structural factor, there is an organizational registration of the social and economic relations of ethnos. The basis of the institutional factor is the ethnic principle that defines the limits of behavior, social norms, spiritual and economic institutions.

The ethnos living in a certain region brings to life a certain sector of economy ethnoeconomy. As we noted, the ethnoeconomy has the huge rationally not used potential. The ethnic forms of managing fulfilled for centuries have adaptability to the changing environment that testifies to their stability.

\section{Discussion}

In figure 1, we present the factors influence on the development of ethnic business.

Let's estimate level of credibility of ethnic businessmen to public authorities (fig. 2). The analysis of figure 2 allows us to reveal the most problem zone of trust - interaction with representatives of law enforcement and supervisory authorities of the region. Low estimates of level of credibility from respondents show it.

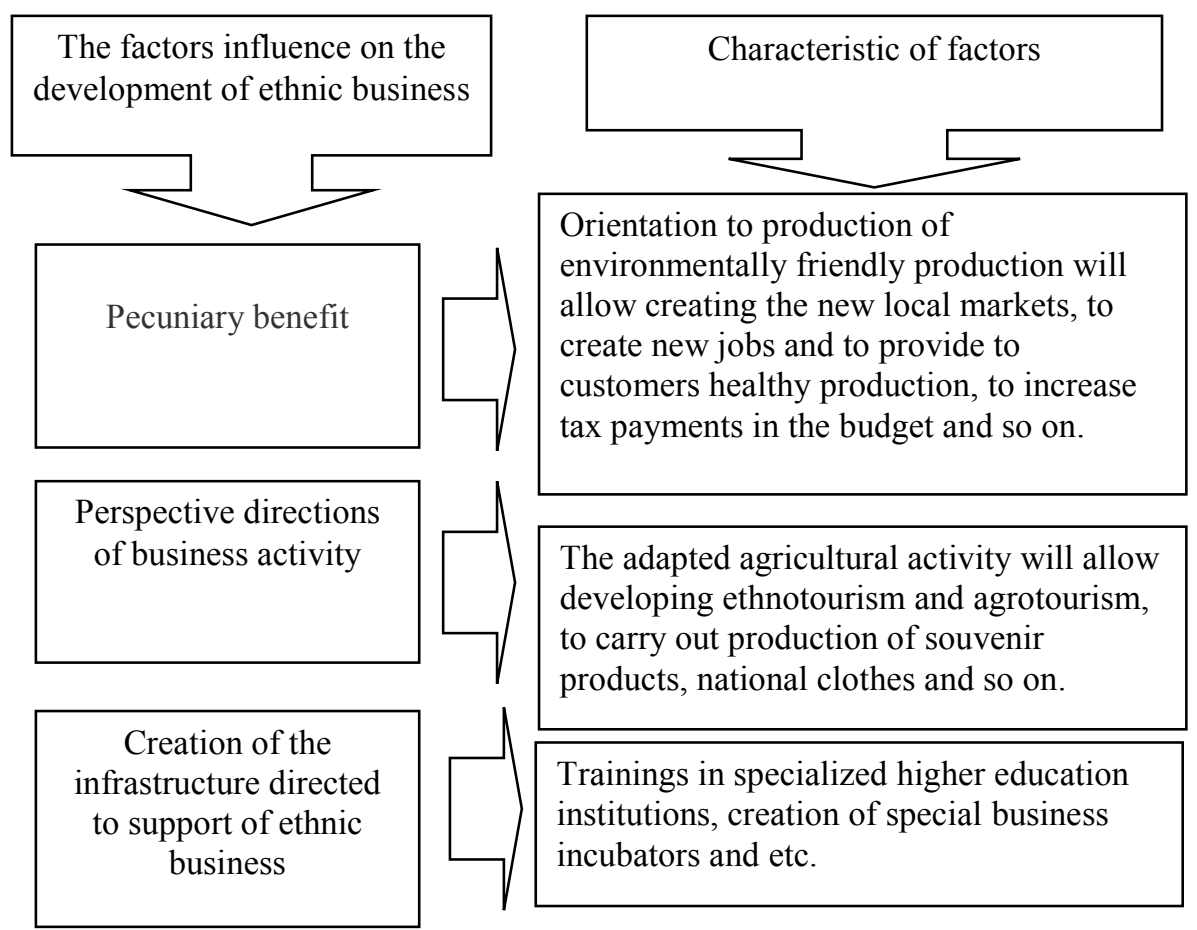

Fig. 1. The factors influence on the development of ethnic business [9]. 


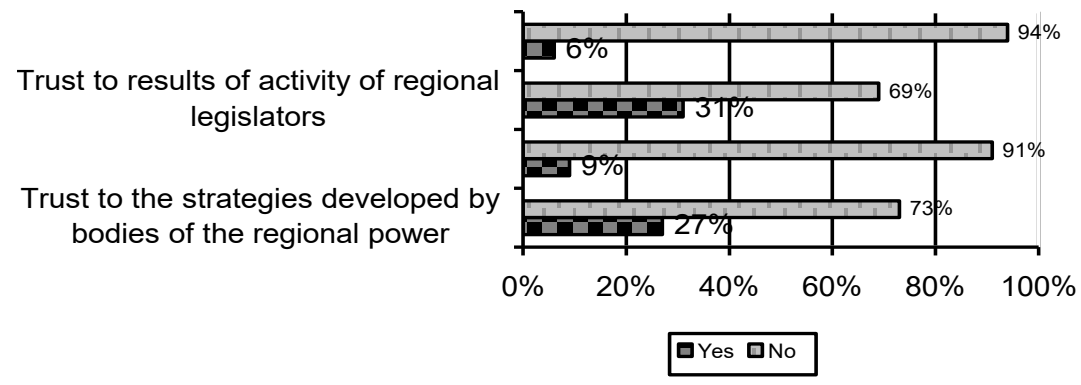

Fig. 2. Level of credibility of ethnic businessmen to the public authorities of the region, $\%$ of the number of respondents [Source: it is made by authors by results of anonymous poll of 45 ethnic businessmen in 2017].

It is no wonder that businessmen look for necessary trust in the family or clan relations (fig. 3).

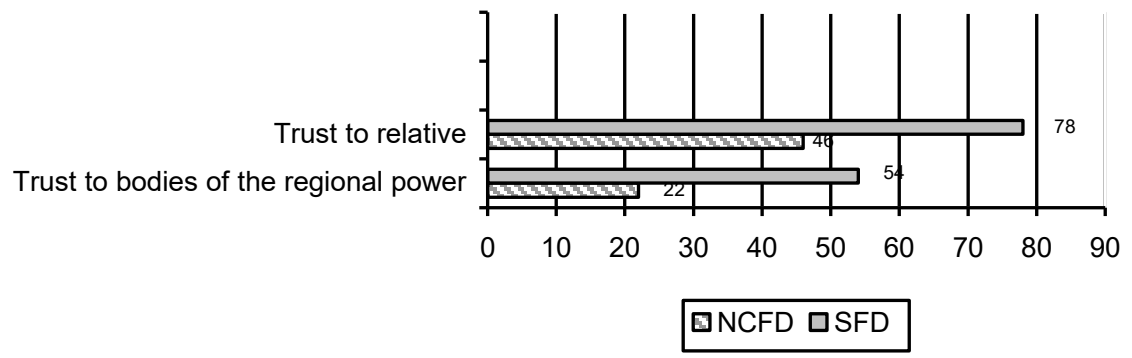

Fig. 3. Mechanisms of compensation of trust by ethnic businessmen, $\%$ of the number of respondents.

The mechanisms presented in figure 3 change trust in clan or family relations depending on the explored district - the Southern Federal District or North Caucasus Federal district. But it does not solve a problem of the lack of confidence to the public authorities of the region.

Let's allocate the main barriers interfering development of ethnic business in regions:

- deficiency of the legislative rules regulating activity of ethnic businessmen;

- absence of institute of mutual trust between public authorities of the region and ethnic businessmen;

- discrepancy of the existing status of ethnic business to the real needs of development of ethnoeconomy for the region;

- lack of strategic contracts between representatives of ethnoeconomy and public authorities of the region.

These barriers allow defining the directions of improvement of an institutional contour of regions. It is possible to strengthen and develop trust between ethnic businessmen and public authorities of the region relying on partnership.

Krasnodar Region puts before itself achievement of the following tasks:

- formation and development of modern innovative infrastructure of the region;

— creation and development of industry research and production base in the region;

— increase in demand for innovations and involvement of private investors to financing of hi-tech projects of the region;

- creation of mechanisms of a conclusion to the market of competitive innovative products and services; 
— promoting of innovative and technological business;

- rendering the state support of economic entities for sustainable development of business [2].

In the sphere of ethnic economy, it is necessary to create prerequisites for a clustering of small and medium forms of business. It will allow not only bringing them closer to the place of production, but also to solve a problem of employment of country people. Adaptation of the population to economic changes will take place quicker.

The main problem of ethnic economy in the Russian Federation - lack of infrastructure on selling of the made ethnic products is revealed. This problem slows down development of production in necessary volumes from "zero". The "successful" ethnic products should have a certain popularity, to be eco-friendly, to conform to certain quality standards, and to possess original packing.

Let's carry out SWOT analysis for the ethnic sector of economy of Krasnodar Region (tab. 1).

Table 1. SWOT-analis of the ethnic sector of economy of Krasnodar Krai.

\begin{tabular}{|c|c|}
\hline $\begin{array}{l}\text { Strengths } \\
\text { Strategically favorable location of the region } \\
\text { Part of the population of the region has skills of } \\
\text { maintaining ethnic economy } \\
\text { Availability of fertile soil and grounds for cultivation } \\
\text { of the cattle } \\
\text { Eco raw materials for production of agricultural } \\
\text { products } \\
\text { Favorable conditions for development of agrotourism, } \\
\text { ethnotourism } \\
\text { The developed areas of accommodation of certain } \\
\text { ethnos that creates conditions for a clustering of } \\
\text { business } \\
\text { Active support sat down from bodies of the regional } \\
\text { power } \\
\text { Well developed transport infrastructure }\end{array}$ & $\begin{array}{l}\text { Weaknesses } \\
\text { The shortage of highly qualified } \\
\text { specialists in ethnic production } \\
\text { The weak marketing policy pursued by } \\
\text { small producers } \\
\text { Unpopularity of brands of ethnic eco } \\
\text { product } \\
\text { Existence of problems in interaction of } \\
\text { public authorities and producers of } \\
\text { agricultural product }\end{array}$ \\
\hline $\begin{array}{l}\text { Opportunities } \\
\text { Active promotion of import substitution programs in } \\
\text { the region } \\
\text { Commercialization of traditional technologies } \\
\text { Use of modern technologies for production of eco } \\
\text { products } \\
\text { Growth of welfare of the population of the region } \\
\text { Advance of ethnic brands from the public authorities } \\
\text { of the region } \\
\text { Creation of platforms of development of agrotourism, } \\
\text { ethnotourism, production of ethnic products in the } \\
\text { region }\end{array}$ & $\begin{array}{l}\text { Threats } \\
\text { Crisis situation in the country } \\
\text { Reduction in demand for ethnic products } \\
\text { The high competition from large } \\
\text { producers of agricultural products } \\
\text { Difficulties of economic and legal } \\
\text { character }\end{array}$ \\
\hline
\end{tabular}

The threats presented in the table 1 can be neutralized with assistance of the public authorities of the region and by means of special work on creation and maintenance of process of functioning of ethnic clusters.

The Cossacks always played an important role in the course of formation of economy of Krasnodar Region. The ideas of revival of traditional Cossack public structures on a register basis are perspective and allow using the hidden reserves of ethnoeconomy of the region.

Let's list conditions of forming of ethnic clusters on the ideas of the Cossack community: 
- existence of a powerful economic basis is necessary;

- it is necessary to carry out correction of an institutional circuit of Krasnodar Region and to revive the Cossacks;

- it is necessary to carry out the organizational work directed to creation of conditions for formation of the Cossack communities;

- it is necessary to carry out comprehensive accounting of the regional all factors allowing revealing optimum land use and distributions of agricultural areas in the Cossack communities.

Let's give definition to the Cossack economy of innovative type. It represents set of the Cossack formations of the region located in close proximity and united by production and economic, infrastructure and other general conditions of activity. This economy has additional competitive benefits at the expense of an opportunity to carry out internal specialization and high extent of cooperation. Such approach allows using the rich enterprise capacity of the region and ethnoeconomic capacity of the Cossack communities.

The feature of functioning of the Cossack farms consists in integration of persons for the purpose of overcoming social isolation of partners and realization of interests of the members. The main principle of activity of similar communities is the principle of a priority of interests of members of the Cossack community. On the one hand, they are owners of integrated economic entity, and on the other hand - employees of this organization.

Need of development of mechanisms of interaction between farmer and cooperative farms which in the last decades make a basis of the Russian agrarian and industrial complex $[4,6,10]$ is defined.

Sustainable development of productive and economic potential is provided by creation of a control system of the Cossack communities. Beglov A.D. developed the approach focused on realization of three key directions. The first direction - improvement of a system of the Cossack self-government for creation of institutional conditions for an effective reproduction cycle of agrarian and industrial complex in communities. The second direction - optimum territorial zoning of regions for the purpose of formation of the natural and resource environment of agro-industrial production. The third direction - development of production and financial cooperation for updating of the fixed business assets of agrarian and industrial complex in the Cossack educations [8].

The first direction represents improvement of a productive and economic system of the Cossack self-government, combining administrative functions, economic functions and involvement of partners for increase in innovative level. This direction promotes creation of effective use of institutional conditions for expansion of a reproduction cycle of agrarian and industrial complex in the Cossack communities [8].

The second direction "Economic System of the Cossack Communities" assumes application of an integrated approach to increase cost efficiency of activity of human resources, updating of the fixed business assets and development of infrastructure of agrarian and industrial complex.

The third direction "Use of Land Resources of the Cossack Communities" assumes restoration of natural and resource potential, maintaining fertility and improvement of the earth. It can be reached using expanded reproduction in the Cossack communities of the region. This direction is focused also on development of economic systems of the Cossack communities on the basis of production and financial cooperation.

Realization of this complex of tasks is based on use of advantages of the cumulative directions. The Cossack self-government allows connecting successfully public and individual interests of Cossacks. Rational land use gives the chance to optimum use the available fixed business assets.

The appeal of the Cossack farms of innovative type is reflected in the figure 4. 


\begin{tabular}{|l|l|}
\hline $\begin{array}{l}\text { Appeal of the } \\
\text { Cossack farms } \\
\text { of innovative } \\
\text { type }\end{array}$ & $\begin{array}{l}\text { Simplification of holding the controlling actions } \\
\text { behind the Cossack enterprises integrated into the } \\
\text { Cossack communities of innovative type }\end{array}$ \\
\cline { 2 - 4 } & $\begin{array}{l}\text { Emergence of additional financial, organizational, } \\
\text { information benefits }\end{array}$ \\
\hline $\begin{array}{l}\text { Creation in the region of new "points" of growth } \\
\text { that create additional opportunities for } \\
\text { development of business within economic space of } \\
\text { the territory }\end{array}$
\end{tabular}

Fig. 4. Appeal of the Cossack farms of innovative type.

Thus, use of model of the Cossack farms of innovative type at the level of the region will allow solving a number of problems:

1) to increase production of agricultural products;

2) to provide inflow of income to the budget;

3) to increase quality of the produced food;

4) to provide growth of competitiveness of regional producers;

5) to increase employment of the population involved in agriculture;

6) the food market will act as "growth point" of the region.

\section{Conclusions}

It is necessary to note that the Cossacks traditionally were the stabilizing factor of social and economic life of regions. With its help, continuous development of the territory due to a number of key signs of the Cossack ethnoeconomic potential was carried out. The main sign - centuries-old experience of maintenance of public safety in multinational regions. The second sign - an integrated approach to use of the most effective forms of government and managing. The third sign - a combination of unique experience of land tenure to ensuring environmental protection with Cossacks. It allows not only making thrifty use of natural resource capacity of the region, but also forming a basis for its development. It is necessary to give the state support to the Cossack communities of innovative type. It will promote effective use of ethnoeconomic capacity of the region.

Measures of the state support from the authorities of the region:

- assistance in updating of the fixed business assets within regional Cossack units;

- support of use of waste-free technologies and the most effective forms of government production;

- identification of the centers of sustainable development of regions at the expense of a clustering of the Cossack settlings.

The main directions of a control system of a reproduction cycle of the agrarian and industrial complex enterprises in the Cossack communities:

- introduction of a system of the Cossack self-government,

- optimization of zoning of regions for preservation of natural and resource potential,

- expansion of a system of the Cossack communities.

Support from public authorities is necessary for each of the presented directions.

The first direction assumes support of activity of the Cossack communities. First, this establishment of standards of development of infrastructure of villages for its complex 
approach to the economic interests of Cossacks. Secondly, support of private Cossack enterprises for ensuring their individual economic interests. The second direction represents an integrated approach to increase in cost efficiency of agrarian and industrial complex with observance of the sparing production mode. The investment of Cossacks with obligations for preservation of the environment is put here. The third direction is focused on providing a reproduction cycle in the Cossack communities.

Realization of all three specified directions will allow developing competitive advantages of Krasnodar Region and will increase investment attractiveness of the region.

\section{References}

1. A.G. Granberg, Region: economy and sociology 1, 87 (2011)

2. Yu.S. Kolesnikov, Bulletin of advisory council 1(8), 47-52 (2017)

3. V.N. Ovchinnikov, N.P. Ketova, Bulletin of the Adygei state university, Series 5: Economy 2(180), 25-34 (2016)

4. V.Ya. Akhmetov, Biospheric economy: theory and practice 2, 40-50 (2017)

5. S.V. Panikarova, Region ethnoeconomy: tendencies, problems and prospects, Monograph (Abakan, 2012)

6. N.M. Surnina, News of the Ural state economic university 1, 111-116 (2012)

7. O.V. Pechura, Municipality: economy and management 1, 13-18 (2012)

8. E.N. Klochko, V.V. Prokhorov, Problem of economy and legal practice 4, 64-67 (2016)

9. E.N. Klochko, V.V. Prokhorov, The Modern Scientific Thought 3, 127-134 (2017)

10. A. Beglov, Renaissance of economic system of the Cossack communities: factors of public administration (Moscow, 2011)

11. E.K. Vorobey, T.G. Borisova, MATEC Web of Conferences "International Science Conference SPbWOSCE-2017 "Business Technologies for Sustainable Urban Development"",01023 (2018) 